\title{
A comparative Study Between the Costs of Polymer Based Rapid Prototyping and Steel Based Manufacture
}

\begin{abstract}
DORIAN NEDELCU*, AUREL BARA, ADRIAN PELLAC, SORIN LAURENTIU BOGDAN
Eftimie Murgu University of Resita, Department of Mechanics and Material Engineering, 1-4 Traian Vuia Sq., 320085 Resita, Romania

The Pelton turbines convert hydraulic energy into mechanical energy, through the Pelton runner, by using high heads and small discharges. The runner has a complex geometry, described in drawings by transversal and longitudinal sections that form continuous surfaces. The SolidWorks software was used to design two Pelton runners: the $R 1$ runner with 21 buckets and the R2 runner with 19 buckets. The runners were made of polymeric materials through the Rapid Prototyping process, using the Objet Desktop 3D printer, which is based on the Objet Poly] et technology, with a layer thickness of 28 microns [1]. The runners were used to measure the hydrodynamic characteristics of a Pelton microturbine on a test rig. The paper aims to highlight the advantages of the Rapid Prototyping process compared to the traditional technology used to manufacture Pelton runners that are intended for experimental research.
\end{abstract}

Keywords: polymer, Rapid Prototyping, Pelton, runner, manufacture, costs

The CAD model of the two Pelton runners was created using the SolidWorks software. The geometry of the V1 Pelton runner, with 21 buckets and of the V2 runner, with 19 buckets, is presented in figure 1[2]. The buckets of the V2 Pelton runner are scaled with a 21/19 ratio on the $X, Y$ and $Z$ directions, maintaining the same characteristic diameter of $148 \mathrm{~mm}[2,3]$.

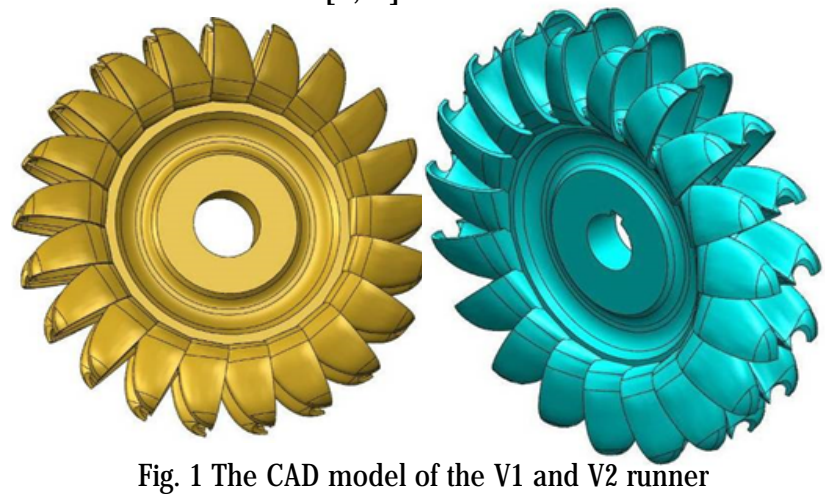

The two Pelton runners were printed on the Objet 3D Printer Multifunctional Desktop 30 in a horizontal position, with the plane of blade symmetry disposed parallel to the printer table. The geometry of the runner that was obtained after removing the support material, figure 2, revealed the high precision of the geometrical details with a small thickness and the high quality of the surfaces. Table 1 shows the printing parameters of the two runners [3].

In the Center for Numerical Simulation \& Digital/Rapid Prototyping (www.csnp.roedu.ro) of the Eftimie Murgu University of Resita, research on a Pelton microturbine, manufactured through rapid prototyping and equipped with the two runners and different nozzles was performed [4], [5].

\section{The Rapid Prototyping cost calculation}

This section presents the cost of the two runners that were obtained through Polyl et Inkjet technology, based partially on the cost estimation algorithm described in [6]. The cost Cost can be divided into five main categories: machine purchase cost allocated to the build $\mathbf{P}$, material $\operatorname{cost} \mathbf{M}$, labour cost $\mathbf{L}_{\mathbf{c}^{\prime}}$, department fixed costs $\mathbf{R}_{\mathbf{s}}$ and profit $\mathbf{P}_{\mathrm{r}}$ :

$$
\text { Cost }=P+M+L_{c}+R_{s}+P_{r}
$$

The machine purchase cost $\mathbf{P}$ is based on the build time of the part. We can assume a useful life of the machine and divide the purchase price equally byall years. Also, the machine builds parts only a fraction of the time during a year. Then, the purchase costfor one build can be calculated as [6]:

\begin{tabular}{|l|c|c|c|}
\hline \multicolumn{1}{|c|}{ Parameter } & U/M & Runner V1 & Runner V2 \\
\hline The characteristic diameter & $\mathrm{mm}$ & 148 & 148 \\
\hline The maximal dimensions & $\mathrm{mm}$ & $182.75 \times 182.68 \times 41.01$ & $186.5 \times 186.5 \times 45.3$ \\
\hline Material & - & VeroWhite polymer & VeroBlue polymer \\
\hline Model material & $\mathrm{g}$ & 766 & 839 \\
\hline Support material & $\mathrm{g}$ & 639 & 726 \\
\hline Printing time & $\mathrm{h} / \mathrm{min}$ & $17 \mathrm{~h}$ & $17 \mathrm{~h} 20 \mathrm{~min}$ \\
\hline Layer thickness (Z-axis) & $\mu \mathrm{m}$ & 28 & 28 \\
\hline Layer's number & - & 1464 & 1671 \\
\hline
\end{tabular}

Table 1

THE PRINTING PARAMETERS OF THE TWO RUNNERS 


$$
P=\frac{M_{a c} \cdot T_{b}}{h_{d} \cdot 365 \cdot Y}
$$

where:

- $M_{\text {ac }}$ is the machine acquisition cost, in Euros;

- $T_{b}$ is the time needed to build a part, in hours; the build time is a function of part size, part shape, number of parts in the build, and the machine's build speed.

- 365 represent the number of days in a year;

- $h$ is the average number of hours per day used by the machine to build parts during one year; in our case, the average build time for a year can be estimated at $2 \mathrm{~h}$ per day; if the machine was acquired for repetitive manufacturing, the average build time per day will increase and this value must be modified consequently;

$Y$ is the useful life of the machine, in years.

The material $\mathbf{M}$ cost can be easily calculated based on the cost of the model and support material per kilogram and the model and support consuption during the build process:

$$
M=c_{v} \cdot\left(M_{c}+S_{c}\right)=c \cdot\left(C_{m} * Q_{m}+C_{s} * Q_{s}\right)
$$

where:

$c_{y}$ is a coefficient for extra material volume that is lost during the build process; typical values range from 1.1 to 1.5;

$\mathrm{M}_{\mathrm{c}}=\mathrm{C}_{\mathrm{m}} * \mathrm{Q}_{\mathrm{m}}$ is the model cost, in Euros;

$\mathrm{C}_{m}$ is the model cost per kilogram;

$\mathrm{Q}_{\mathrm{m}}^{\mathrm{m}}$ is the model consumption, in kilograms;

$\mathrm{S}_{\mathrm{c}}=\mathrm{C}_{\mathrm{s}} * \mathrm{Q}_{\mathrm{s}}$ is the support cost, in Euros;

$C_{s}^{c}$ is the support cost per kilogram;

$\mathrm{Q}_{\mathrm{s}}^{\mathrm{s}}$ is the support consumption, in kilograms.

Usually, the model and support material are delivered in packs of 2 and, for only one kit acquisition, the cost also includes transport.

The labour cost $\mathrm{L}$ is the time required for employees to set up the build, remove the fabricated parts, clean the

Table 2

\begin{tabular}{|c|c|c|c|c|c|}
\hline $\begin{array}{c}\text { Cost } \\
\text { component }\end{array}$ & Cost element & Symbol & $\mathbf{U} / \mathbf{M}$ & Runner Vl & Runner V2 \\
\hline \multirow{5}{*}{$\begin{array}{l}\text { Machine } \\
\text { purchase }\end{array}$} & Machine acquisition cost & $M_{a c}$ & Euro & 40000 & 40000 \\
\hline & Useful life of the machine & $\mathrm{Y}$ & years & 5 & 5 \\
\hline & Typical up-time percentage & $h_{d}$ & hours & 2 & 2 \\
\hline & Time for part build & $T_{b}$ & hours & 17 & 17.3 \\
\hline & Machine purchase cost & $P$ & Euro & 186 & 190 \\
\hline \multirow{10}{*}{ Material cost } & Model consumable name & - & - & VeroWhite & VeroBlue \\
\hline & Support consumable name & - & - & \multicolumn{2}{|c|}{ FullCure 705 Support Resin } \\
\hline & Model cost $/ \mathrm{kg}$ & $C_{m}$ & Euro/kg & 483 & 483 \\
\hline & Model consumption & $Q_{m}$ & $\mathrm{~kg}$ & 0.766 & 0.839 \\
\hline & Model cost & $M_{c}$ & Euro & 370 & 405 \\
\hline & Support cost $/ \mathrm{kg}$ & $C_{s}$ & Euro/kg & 243 & 243 \\
\hline & Support consumption & $Q_{s}$ & $\mathrm{~kg}$ & 0.639 & 0.726 \\
\hline & Support cost & $S_{c}$ & Euro & 155 & 176 \\
\hline & Loss coefficient & $c_{v}$ & $\%$ & 1.2 & 1.2 \\
\hline & Material cost & $\mathrm{M}$ & Euro & 630 & 698 \\
\hline \multirow{4}{*}{ Labor cost } & Number of employees & $\mathrm{N}$ & No. & 1 & 1 \\
\hline & Cost per hour & $C_{h}$ & Euro/hour & 10 & 10 \\
\hline & Work hours & $W_{h}$ & hours & 3 & 3 \\
\hline & Labor cost & $L_{c}$ & Euro & 30 & 30 \\
\hline
\end{tabular}

THE RAPID PROTOTYPING COST CALCULATION 


\begin{tabular}{|c|l|c|c|c|c|}
\hline $\begin{array}{c}\text { The } \\
\text { department } \\
\text { fixed cost }\end{array}$ & The fixed percentage & $R_{s \%}$ & $\%$ & 15 & 15 \\
\cline { 2 - 6 } & The fixed cost & $R_{s}$ & Euro & $\mathbf{1 2 7}$ & $\mathbf{1 3 8}$ \\
\hline \multirow{2}{*}{ Profit } & The profit percentage & $P_{r \%}$ & $\%$ & 10 & 10 \\
\cline { 2 - 6 } & The profit & $P_{r}$ & Euro & $\mathbf{9 7}$ & $\mathbf{1 0 6}$ \\
\hline- & Final cost & Cost & Euro & $\mathbf{1 0 7 1}$ & $\mathbf{1 1 6 1}$ \\
\hline
\end{tabular}

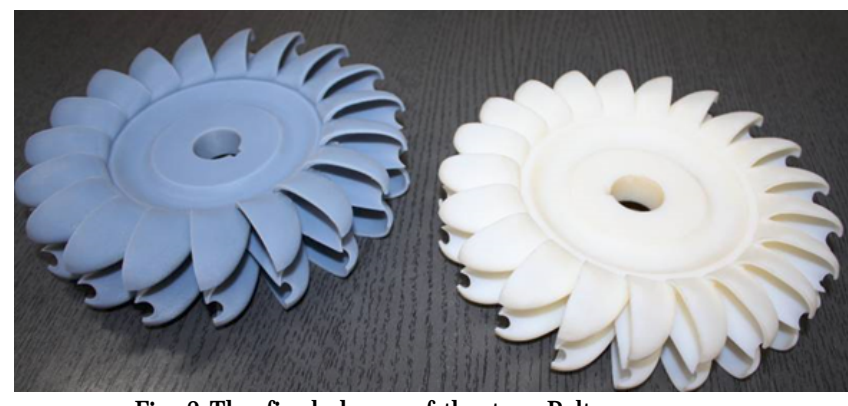

Fig. 2 The final shape of the two Pelton runners

parts, clean the machine and get the machine ready for the next build.

where:

$$
L_{c}=N \cdot C_{h} \cdot W_{h}
$$

$\mathrm{N}$ is the number of employees allocated to the build process;

$C_{\text {is }}$ ise employee's salary per hour, in Euros/hour;

$W_{h}$ is the number of hours worked by the employees, in hours.

The department fixed costs $R_{s}$ take into account the energy cost, service and maintenance costs and other general costs of a department.

$$
R_{s}=R_{s \%} \cdot\left(P+M+L_{c}\right)
$$

The profit $P_{r}$ can be calculated through the profit percentage $P$

Table 2 shows the Rapid Prototyping cost calculation.

\section{The Manufacturing cost calculation}

This section presents the technology that was used for the execution and the method that was used to calculate the costs of a Pelton runner, starting from the raw material type X3CrNiMo13-4 [7].

The costs can be divided into four categories: the

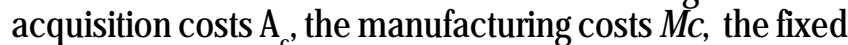
costs $F_{c}$ and the collaboration costs $C_{\text {. }}$.

$$
\text { Cost }=A_{c}+M_{c}+F_{c}+C_{c} \text { [Euro] }
$$

The acquisition costs $A$ consist of the raw material price $R_{m c}$ and the transport costs $T_{c}$.

$$
A_{c}=R_{m c}+T_{c} \text { [Euro] }
$$

The manufacturing costs $M_{c}$ consist of:

where:

$$
M_{c}=L_{c}+U_{c}+H_{t c} \text { [Euro] }
$$

- $L$ represents the labour costs, which consist of the price for the following technical operations:

- cutting of the material;

- turning at the requested dimensions; due to the complexity of the runner, the use of a CNC turning lathe machine is necessary for this operation;

- grinding of the internal diameter; the grinding operation will be done on a conventional grinding machine;

- execution of the keyway;

- milling rotor blades; this operation requires the use of a CNC milling machine in five axes.

The necessary time for all operations is $100 \mathrm{~h}$.

- U represents the cost of utilities;

- $H_{\text {tc }}^{c}$ represents the costs for the stress relieving heat treatment.

The fixed costs $F$ implies the service and maintenance prices and other general costs of the company [8].

The collaboration costs refer to the price for external collaboration. In our situation, it is the price paid to balance the runner.

The final cost will be calculated as follows:

where $P_{r}$ is the profit.

$$
\mathrm{P}=\text { Cost }+\mathrm{P}_{\mathrm{r}}
$$

The profit will be calculated through the profit percentage:

$$
P_{r}=P_{r} \% \text { Cost }
$$

\begin{tabular}{|c|c|c|c|}
\hline Cost component & Cost element & Symbol & Value (Euro) \\
\hline \multirow{2}{*}{ Acquisition cost $\left(A_{c}\right)$} & Raw material & $A_{c}$ & 105 \\
\hline & Transport cost & $T_{c}$ & 60 \\
\hline \multirow{3}{*}{ Manufacturing cost $\left(\mathrm{M}_{\mathrm{c}}\right)$} & Labour cost & $\mathrm{L}_{\mathrm{c}}$ & 322 \\
\hline & Cost of utilities & $\mathrm{U}_{\mathrm{c}}$ & 347 \\
\hline & Heat treatment cost & $\mathrm{H}_{\mathrm{tc}}$ & 250 \\
\hline Fixed cost & & $F_{c}$ & 732 \\
\hline Collaboration cost & & $\mathrm{C}_{\mathrm{c}}$ & 120 \\
\hline \multicolumn{3}{|r|}{ Cost } & 1936 \\
\hline \multirow{2}{*}{ Profit } & The profit percentage & $\mathrm{P}_{\mathrm{r}} \%$ & $10 \%$ \\
\hline & The profit & $\mathrm{P}_{\mathrm{r}}$ (Euro) & 193.6 \\
\hline \multicolumn{3}{|c|}{ Final cost (Euro) } & 2129.6 \\
\hline
\end{tabular}

The cost calculation for the execution of the Pelton runner is presented in table 3.

To finalize the runner geometry, a minimum of 10 people are involved in the following operations: the auction of the material acquisition, the material cutting, the turning, the rectification, the milling, the locksmithing, the runner
Table 3

THE

MANUFACTORING COST CALCULATION 
Table 4

THE COMPARATIVE RESULTS BETWEEN RAPID PROTOTYPING AND THE MANUFACTURING PROCESS

\begin{tabular}{|l|c|c|c|}
\hline \multicolumn{1}{|c|}{ Parameter } & U/M & Rapid Prototyping process & Manufacturing process \\
\hline Material type & - & Polymer & X3CrNiMo13-4 \\
\hline Material cost & Euro & $630 / 698$ & 105 \\
\hline Build time & h & $\sim 17 / 17 \mathrm{~h} 20 \mathrm{~min}$ & $\sim 100$ \\
\hline Number of employees & No. & 1 & Minimum 10 \\
\hline Final cost & Euro & $1071 / 1161$ & 2129.6 \\
\hline
\end{tabular}

balancing, CNC programmer, the technologist, the CTC control.

\section{Rapid Prototyping versus Manufacturing}

Table 4 shows the main conclusions of this comparative study:

- the time of the process is six time smaller for the

Rapid Prototyping technology;

- the number of required employees is ten times bigger

for the classic process compared to the Rapid Prototyping

technology;

- the final cost of the Rapid Prototyping technology is half of the classic manufacturing process cost, even if the material cost is six times bigger.

\section{Conclusions}

Experimental research on hydraulic turbine runners involves the alteration of their geometries in order to find the optimal one. The two runners were used to measure the hydrodynamic characteristics of a Pelton microturbine on a test rig [5]. The runner's geometry, created through Rapid Prototyping technology, withstood all experimental tests very well, without registering any incident during the experiments, even for the maximum test speed of 3000 rpm. In the experimental research area, Rapid Prototyping technology is an alternative solution for microturbine components fabrication, offering a high precision (0.1 $\mathrm{mm})$, fast and cheap manufacture of these geometries.

\section{References}

1.*** Polyl et ${ }^{\mathrm{TM}}$ Materials Data Sheet, 2014.
2.NEDELCU, D., POP, F.M., COJ OCARU, V., HOPOTA, A., Rapid prototyping of a Pelton runner, A XII-a Conferinta Nationala multidiciplinara - cu participare international Profesorul Dorin PAVEL - fondatorul hidroenergeticii romanesti, Sebes, 2012, ISSN 2067-7138. 3.NEDELCU, D., AVASILOAIE, R., FLOREA, D., RAJIC, A., Applications of the Rapid Prototyping Technology to Manufacture the Pelton Runners, Eftimie Murgu University of Resita, Year XX, No. 1, 2013, ISSN 1453 7397.

4.NEDELCU, D., COJ OCARU, V., GHICAN, A., PERIS-BENDU, F., AVASILOAIE, R., Considerations Regarding the Use of Polymers for the Rapid Prototyping of the Hydraulic Turbine Runners Designed for Experimental Research on the Model, Mat. Plast., 52, no. 4, 2015, p. 475

5.AVASILOAIE, R., Theoretical and experimental research on microturbines for high head and low discharges, PhD thesis, Eftimie Murgu University of Resita, 2013.

6.GIBSON, I., ROSEN, D.W., STUCKER, B., Additive Manufacturing Technologies, Rapid Prototyping to Direct Digital Manufacturing, Springer, ISBN: 978-1-4419-1119-3.

7.BORDEASU, I., MICU, L.M., MITELEA, I., UTU, I.D., PIRVULESCU, L.D., SIRBU N.A., Cavitation Erosion of HVOF Metal-ceramic Composite Coatings Deposited onto Duplex Stainless Steel Substrate, Mat. Plast., 53, no.4, 2016, p.781

8.POPESCU, T. C., DUMITRESCU, C., BORDEASU, I., Aspects Concerning the Use of Plastics in Developing Test Stands for Experimental Models of Hydraulic Turbine Blades and Rotors, Mat. Plast., 53, no.1, 2016, p.174

Manuscript received: 6.03 .2017 